\title{
New Stabilizers for Poly(vinyl chloride) Derived from 1,1 -Bis (4-aminophenyl) - 4-Phenyl Cyclohexane Compounds[II]
}

\author{
Hussein N. Salman ${ }^{1}$, Olfat A. Nief ${ }^{1^{*}}$ and Ahmed A. Ahmed ${ }^{2}$ \\ ${ }^{1}$ Department of Chemistry, College of Science, Al- Mustansiriyah University, Baghdad-Iraq. \\ ${ }^{2}$ Polymer Research Unit, Al- Mustansiriyah University, Baghdad-Iraq. \\ * Corresponding Author : olfat_nife@uomustansiriyah.edu.iq
}

\begin{abstract}
This article included the photostabilization study for poly(vinyl chloride) by using newly stabilizers derived from [1,1 -Bis (4-aminophenyl)-4-Phenyl Cyclohexane] as additives against photodegradation. For that purpose, many samples (films) has been prepared by adding additives to the poly(vinyl chloride) with different weight percentages from additives and by different thickness. The photostabilization activities of these compounds were determined by detecting the carbonyl group (The position of carbonyl absorption is specified at $1724-1770 \mathrm{~cm}^{-1}$ ) with irradiation time. The absorption spectra of poly vinyl chloride films were followed using Shimadzu Spectrophotometer Also, change the viscosity of the average molecular weight and the degree of deterioration $(\alpha)$ and the average number of chain scission (s) was studied .We found through results that the rate of photostabilization in the presence of additives follows the following trend:-
\end{abstract}

\section{$\mathrm{C} 4>\mathrm{C} 3>\mathrm{C} 2>\mathrm{C} 1>\mathrm{PVC}$}

UV absorption peroxide decomposer, for mechanisms haven been suggested according to experimental results obtained.

[DOI: 10.22401/JNUS.21.3.07]

Keywords: Photostabilizers, photochemistry, $[1,3]$ oxazepine, poly(vinyl chloride).

\section{Introduction:}

Photochemical reaction is a reaction that initiated using absorption off light. Then reaction may then begin with or without incessant irradiation. The photochemical reaction arises from the absorption of light, which places the reactant molecules into an excited state. These molecules may then experience a variety of subsequent reactions to products formation [1]. This reactivity is usually not observed in then ground state, i.e. when no light has been absorbed, on the other hand, very slow thermal reactions may occur [2]. It is widely recognized that ultraviolet radiation (UV) in sunlight (wavelengths between $280 \mathrm{~nm}$ and $400 \mathrm{~nm}$ ) is an important factor causing photodegradation too some organic polymers such as poly vinyl chloride [3]. UV radiation causes photo oxidative degradation which results in breakdown of polymeric $(\mathrm{C}-\mathrm{C})$ bonds, and produces free radical and reduces the molecular weights, causing deterioration off mechanical properties and leading too useless materials, after an unpredictable times [4,5] Poly(vinyl chloride) is ones of then important commercial polymers, commonlys used in many industrial fields which including electronic, architecture, chemical engineering, transportation and packaging [6,7] When exposed vinyl chloride polymers too light at $250-350 \mathrm{~nm}$ typical signs off degradation appears in polymer samples [8] and include the following. physical properties such ass loss of impact strength, changes in color, cracking, loss of elongation and tensile strength or chalking off the surface. For example, garden chairs lose their gloss and become brittle, the color of stadium seats appears chalky and some plastics will be yellow and cracked.

To avoid degradation plastic when UV light absorbed are used UV stabilizers have been developed and are added to a polymer to inhibit the photoinitiation processes. There are three types: Ultraviolet Absorbers, Quenchers and Hindered Amines Light Stabilizers (HALS). Organic compounds such as benzophenones and benzotriazoles are typical absorbers which selectively absorb the UV and re-emit at a less harmful wavelength [9]

The photostabilization off PVC was studied using a new heterocyclic compounds containing 1,3-oxazepine and 1,3,4oxadiazole, heterocyclic compounds stabilizes PVC by various mechanisms. for examples UV absorber, screener or by radical scavenger. 
These stabilizers provide good long-term stability and are usually referred to these mechanisms [10-13].

In this article, four compounds of diamine derivatives have been synthesized by the method previously described by Nief et al [14]. and studied their uses as a photostabilizers for poly(vinyl chloride).

\section{Materials and methods:}

\subsection{Materials:}

1,1

Cyclohexane

-Bis(4-aminophenyl)-4-Phenyl

phenylcyclohexane-1,1-diyl)bis(4,1- phenylene))bis(azanylylidene))bis(methanylyli dene)) dibenzaldehyde (C2), 4,4'-(((4phenylcyclohexane-1,1-diyl)bis(4,1-

phenylene))bis(4,7-dioxo-2,3,4,7-tetrahydro1,3-oxazepine-3,2-diyl))dibenzaldehyde (C3), 4,4'-(((4-phenylcyclohexane-1,1-diyl)bis(4,1phenylene))bis(1,5-dioxo-1,3,4,5tetrahydrobenzo[e][1,3]oxazepine-4,3-diyl)) dibenzalde $(\mathrm{C} 4)$ were prepared by the method previously described by Nief et al [14].

Table (1)

Symbol, name and structural formula of compounds.

\begin{tabular}{|c|c|c|}
\hline $\begin{array}{c}\text { Symbol } \\
\text { Compound }\end{array}$ & Structural Formula of Compound & Name of Compound \\
\hline C1 & & $\begin{array}{l}\text { 1,1-Bis (4-aminophenyl) -4-Phenyl } \\
\text { Cyclohexane }\end{array}$ \\
\hline C2 & & $\begin{array}{l}\text { 4,4'-((((4-phenylcyclohexane-1,1-diyl) } \\
\text { bis(4,1-phenylene })) \text { bis(azanylylidene })) \\
\text { bis(methanylylidene })) \text { dibenzaldehyde }\end{array}$ \\
\hline $\mathbf{C 3}$ & $\mathrm{HO}$ & $\begin{array}{l}\text { 4,4'-(((4-phenylcyclohexane-1,1-diyl) } \\
\text { bis(4,1-phenylene))bis(4,7-dioxo- } \\
\text { 2,3,4,7-tetrahydro-1,3-oxazepine-3,2- } \\
\text { diyl)) dibenzaldehyde }\end{array}$ \\
\hline C4 & $\begin{array}{l}0 \\
-\mathrm{CH} \\
-\mathrm{CH}\end{array}$ & $\begin{array}{c}\text { 4,4'-(((4-phenylcyclohexane-1,1-diyl) } \\
\text { bis(4,1-phenylene))bis(1,5-dioxo- } \\
1,3,4,5- \\
\text { tetrahydrobenzo[e][1,3] oxazepine-4,3- } \\
\text { diyl))dibenzaldehyde }\end{array}$ \\
\hline
\end{tabular}

\subsection{Irradiation Experiments:}

\subsection{1. method of preparation Films:}

Solutions of poly(vinyl chloride) (PVC supplied Company in Turkey by Petkim) $(0.5 \% \mathrm{w} / \mathrm{v})$ in tetrahydrofuran (THF) as solvents were used to prepare $(40 \mu \mathrm{m})$ thickness of polymer films. The films were prepared by evaporation technique at room temperatures for 24 hours, to remove the possible residual tetrahydrofuran solvent. After the PVC solutions were prepared, and poured into glass frame. This frame was made by glue the laboratory glass's slides onto a piece of regular glass, to obtain small sinks, their volume is $(4 \mathrm{ml})$.

After then evaporation off solvent, that's led to formation of polymer films. The thickness of these films is about $(40 \mu \mathrm{m})$, these films were paste onto cartoon papers, these papers contain hole in dimension $(2 \times 2 \mathrm{~cm})$.

\subsubsection{Accelerated Testing Technique:}

An accelerated weather-meters Q-panel Laboratory ultraviolet (QUV; Q-Panel Company, Homestead, Florida, USA) for irradiation of poly vinyl chloride films and 
provided by Q-plate company. The accelerated weathering test containse a stainless steel plate that has one hole in the back side and two others in the front. Each side contains lamp (type Fluorescent Ultraviolet Lights) 40 Watt each (Q-Panel Company), giving wavelength range between (250 to380 $\mathrm{nm})$ and the maximum wavelength light intensity is at (6.4*10-7 Ein dm-3 S-1).The poly vinyl chloride films were fixed parallel to the lamps and vertically too make sure that UV incident radiation is perpendicular on the samples, the irradiated films were rotated from time to time to ensure that the intensity of light incident on all samples is the same. The distance between then polymer films and the source was (10 $\mathrm{cm})[15]$.

\subsubsection{Photodegradation measuring methods:}

The photodegradation of poly vinyl chloride film were followed using Shimadzu Spectrophotometer. Then absorption spectra off poly vinyl chloride films were recorded in the range of (4000-400) cm-1.The position of carbonyl absorption is specified at $(1730 \mathrm{~cm}$ 1) $[16,17]$. The progress of photodegradation through different irradiation times were followed by noting changes in carbonyl peaks. Then carbonyl indexes (ICO) were calculated by comparison off the FTIR absorption peaks at $1722 \mathrm{~cm}-1$ with reference peaks at (1328 $\mathrm{cm}-1$ ), respectively. This method is called band index method which includes as equation (1).

$$
\mathrm{I}_{\mathrm{s}}=\frac{\mathrm{A}_{\mathrm{s}}}{\mathrm{A}_{\mathrm{r}}}
$$

where: $A s=$ absorbance of the band under study.

$\mathrm{Ar}=$ absorbance of the reference band.

Is = group index under study.

[The actual absorbance difference between the absorbance of the highest peak and the baseline (A Top beak-base line) is calculated using then baseline method [18], [19].

\subsubsection{Viscosity -Average Molecular Weight Determination:}

The intrinsic viscosity, $\eta$ as function of average molecular weight, $\mathrm{M}$ is represented by Mark-Houwink-Sakurada equations (2) $[20$ 22].

$$
[\eta]=K\left(\bar{M}_{v}\right)^{\alpha^{\prime}}
$$

where $\mathrm{K}$ and $\alpha$ are constants for a given polymer-solvent-temperature system.

Intrinsic viscosity was examined using the U-tube Ostwald viscometer which allows the reading of flow times of the polymer solution (t) and the solvent is pure(to). the following viscosities were determined using then equation given;

Relative viscosity, $\eta \mathrm{rel}=\mathrm{t} / \mathrm{to}$

Specific viscosity $\eta \mathrm{sp}=(\mathrm{t} / \mathrm{to})-1$

intrinsic viscosity, $\eta=(\sqrt{ } 2 / c)(\eta s p-\eta r e) 1 / 2$

The quantum yields of main chain scission (фcs) was calculated from viscosity measurement using the following relation [23].

$(\phi c s)=(\mathrm{CA} / \mathrm{Mv}, \mathrm{o})[([\eta 0] /[\eta] 1 / \alpha-1] / \mathrm{Iot}$

Where: C=concentrations; $A=$ Avogadro's numbers; $(\mathrm{Mv}, \mathrm{o})=$ the initial viscosity

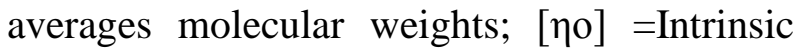
viscosity of PVC polymer before irradiation; Io=Incident intensity (6.4*10-7 Ein. dm-3.s-1) and $\mathrm{t}=$ Irradiation time in second .

\section{Results and Discussion}

Compounds [C1-C4] were used as additives for then photostabilization off PVC films. The irradiation of PVC films with UV light at wavelength $=313 \mathrm{~nm}$, led to appearance of bands at $\left(1770 \mathrm{~cm}^{-1}\right)$ and $\left(1724 \mathrm{~cm}^{-1}\right)$ was attributed to the formation of carbonyl groups related to carbonyl compounds such as (chloroketone and aliphatic ketone). [24]

The carbonyl index was monitored as a function off irradiation times using FTIR spectrophotometry.

The PVC films was irritated produced a clear change in the FTIR spectrum. Fig.(1) show then change in IR-spectra of PVC film without additives and in the presence of $0.5 \%$ additives respectively. 


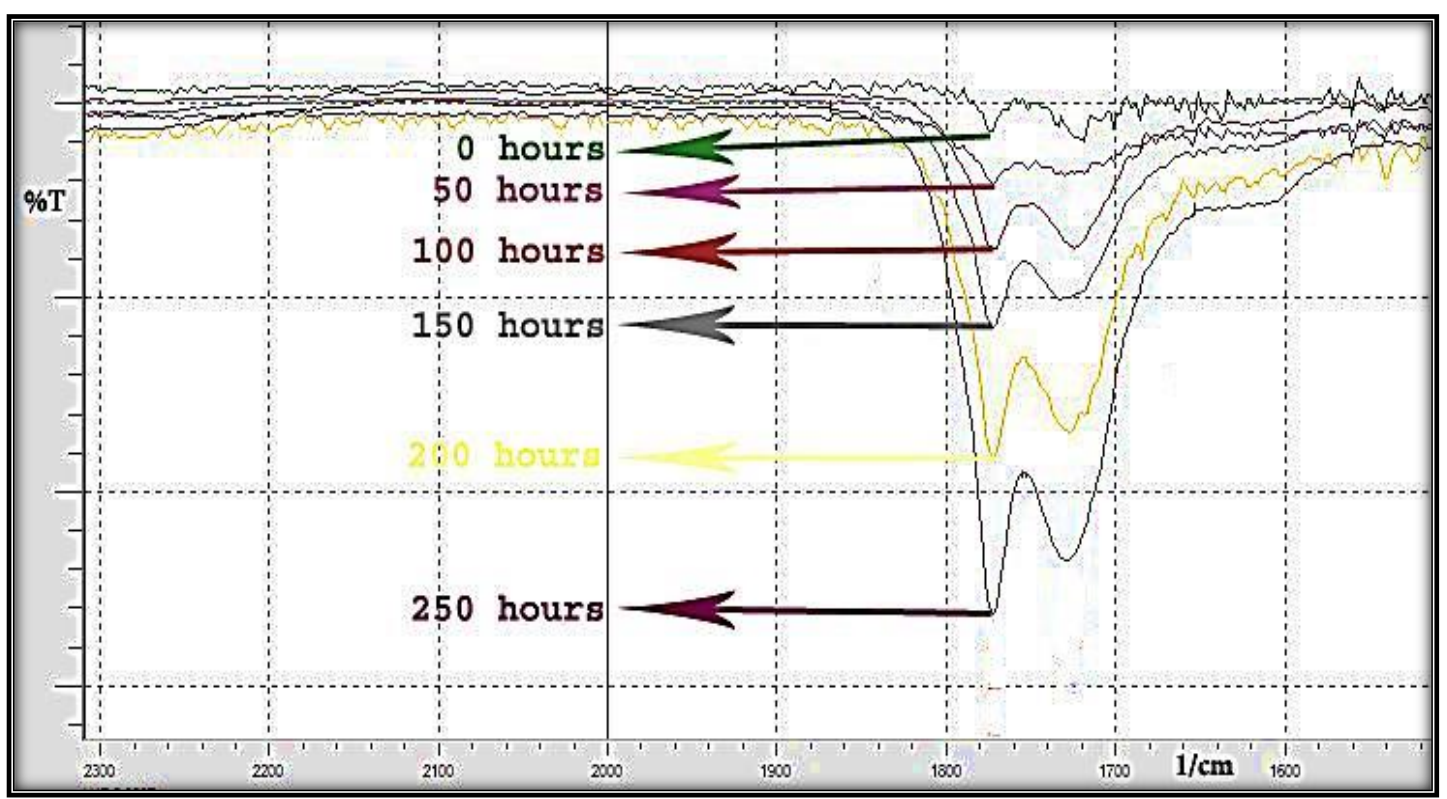

Fig.(1): FT-IR Spectra of PVC samples stabilized with 0.5\% (C4) at (40 $\mu$ m thickness) under UV degraded for different exposure time.

The changes، in the intensities off the stretching absorptions bands of the carbonyl group was used to follow then extent off polymers degradation during irradiation, because then intensities off these bands are directly proportional to the extents of degradation [25]

Results figures (2-5) show that the carbonyl index (ICO) are decreasing with increase weight ratio concentration of additives and shown that additive concentrations of $0.5 \%$ by weight gave، the best results.

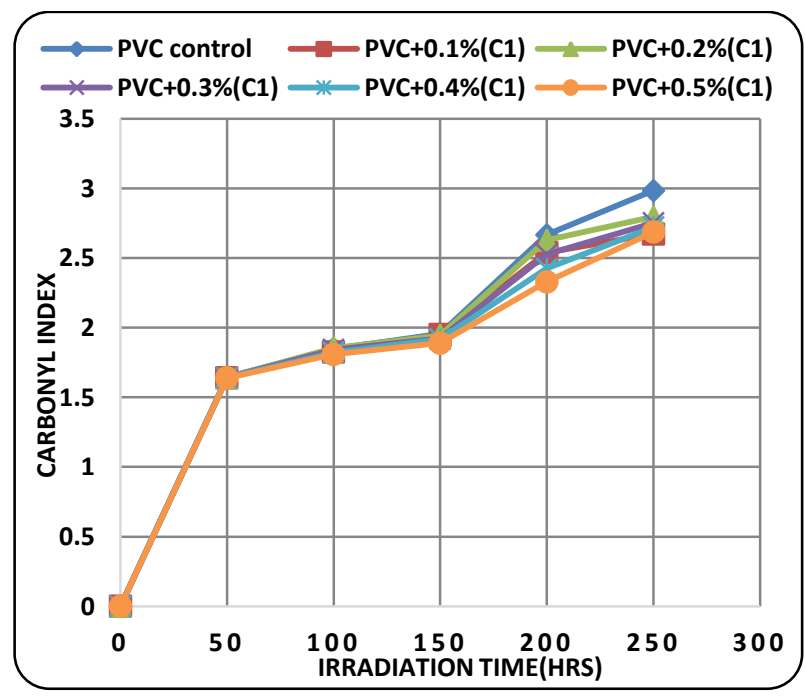

Fig.(2): The relationship between the carbonyl index and irradiation time for PVC

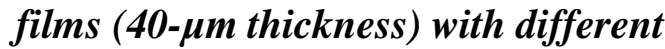
concentration (0.1-0.5\% for C1 additive).

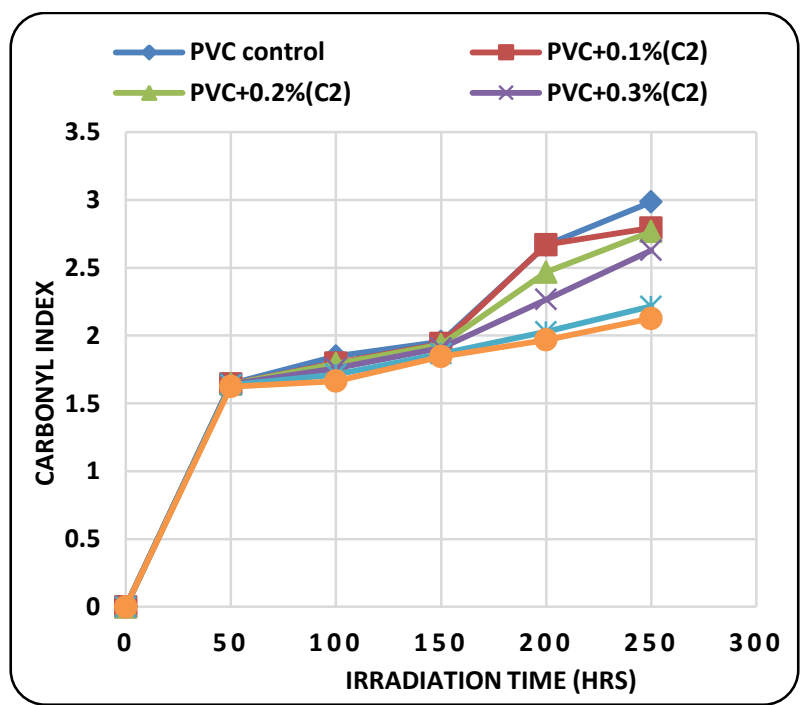

Fig.(3): The relationship between the carbonyl index and irradiation time for PVC films (40- $\mu m$ thickness) with different concentration (0.1-0.5\% for C2 additive). 


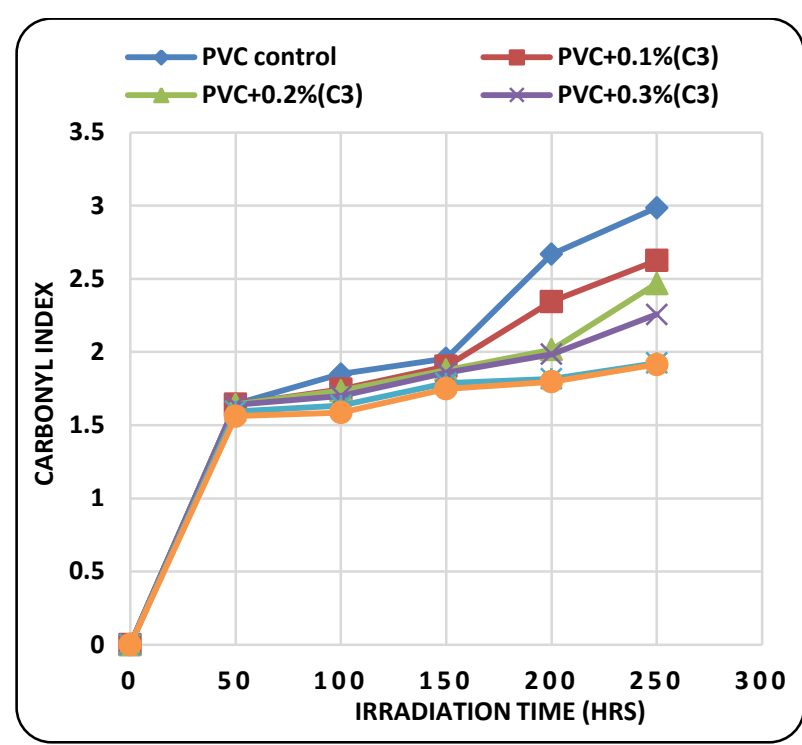

Fig.( ()): The relationship between the carbonyl index and irradiation time for PVC films (40- $\mu m$ thickness) with different concentration (0.1-0.5\% for $\mathrm{C} 3$ additive).

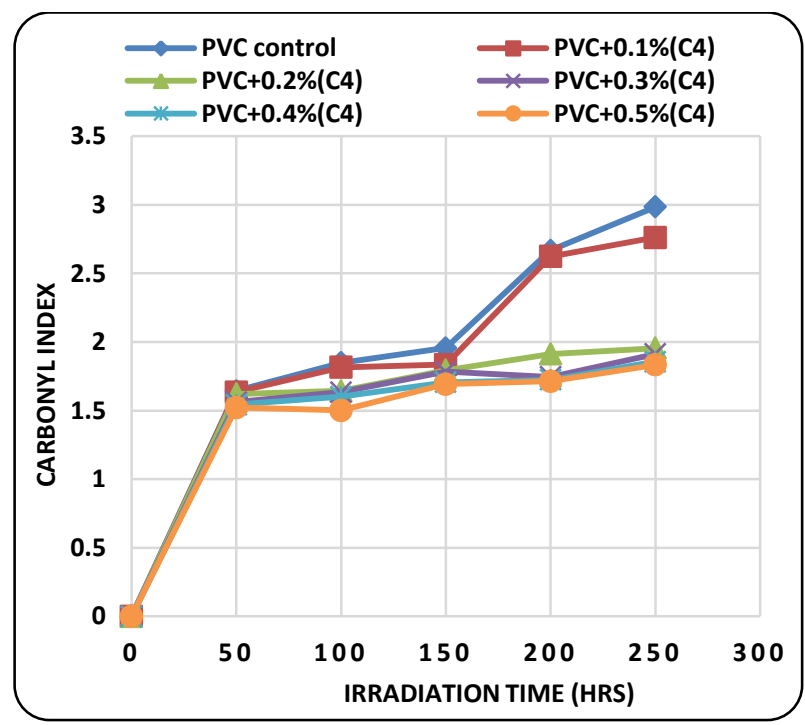

Fig.( ( )): The relationship between the carbonyl index and irradiation time for PVC

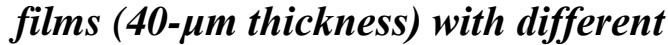
concentration (0.1-0.5\% for $\mathrm{C} 4$ additive).

The photodegradation rate off PVC films was studied in different thickness of $(40,70,100 \mu \mathrm{m})$ without and with fixed concentration of $(0.5 \%)$ of additive. The relationships between then carbonyl index with irradiation time are shown' in figures (6-9). The results shown in figures (6-9) indicate that the rate of photo-oxidation (carbonyl index) at fixed irradiation time steadily decrease with the increase of film thickness for additive used and so dose that of the PVC control.Fig.(9) show the relationships between the carbonyl index (ICO) with thickness film which indicate the decrease of photodegradation with the increase of thickness of the film.

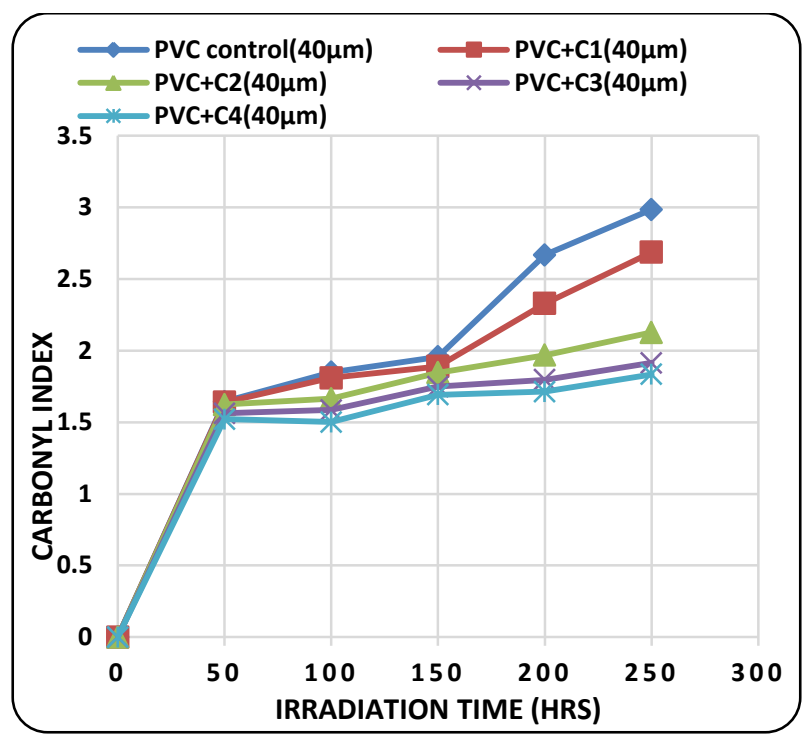

Fig.(6): The relationship between carbonyl index and irradiation time for PVC films with thickness (40 $\mu \mathrm{m}$ ) and that containing 0.5 wt\% of additives.

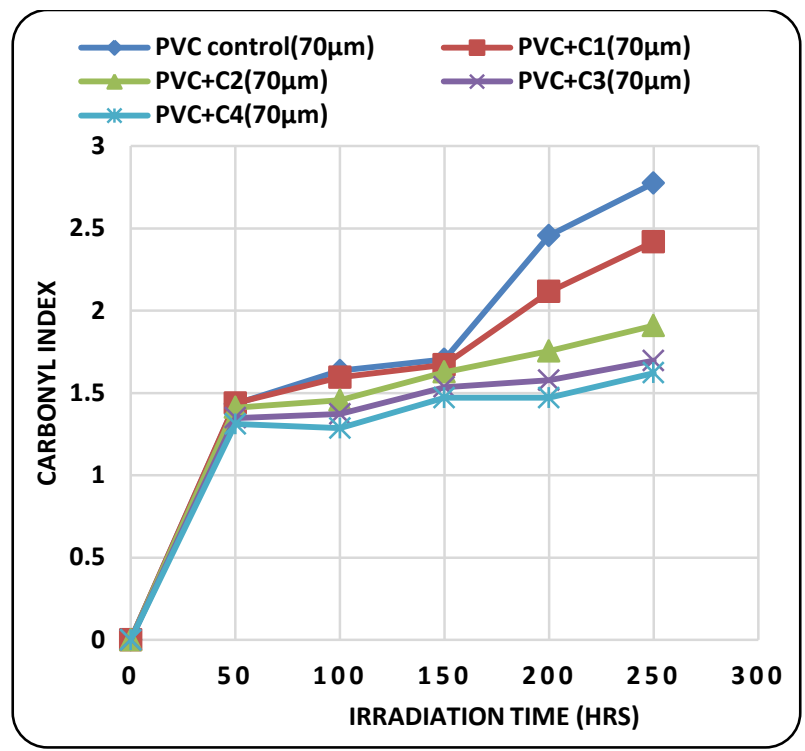

Fig.(7): The relationship between carbonyl index and irradiation time for PVC films with thickness $(70 \mu \mathrm{m})$ and that containing 0.5 wt\% of additives. 


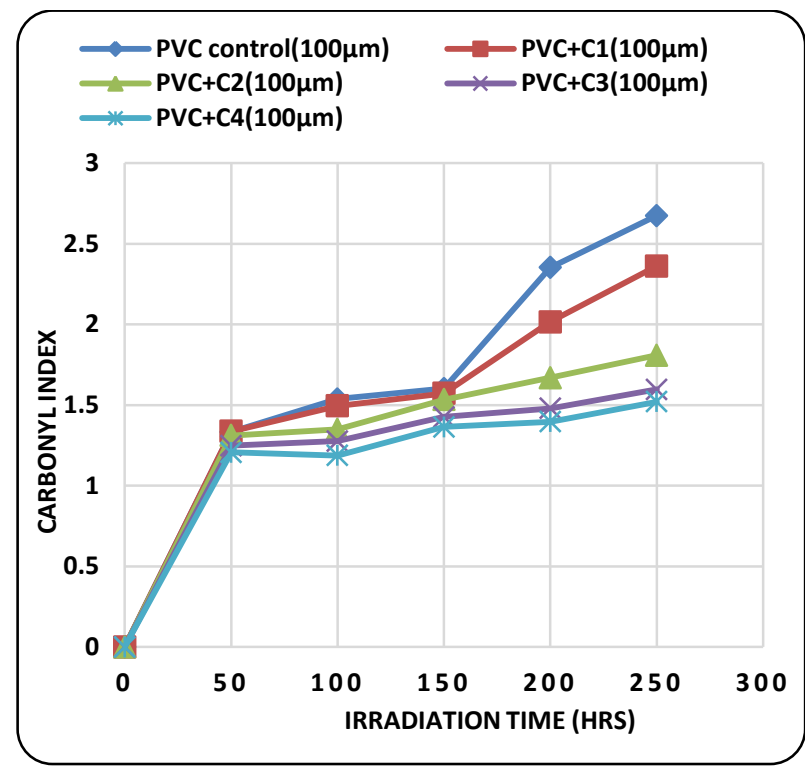

Fig.(8): The relationship between carbonyl index and irradiation time for PVC films with thickness (100 $\mu \mathrm{m})$ and that containing 0.5 wt\% of additives.

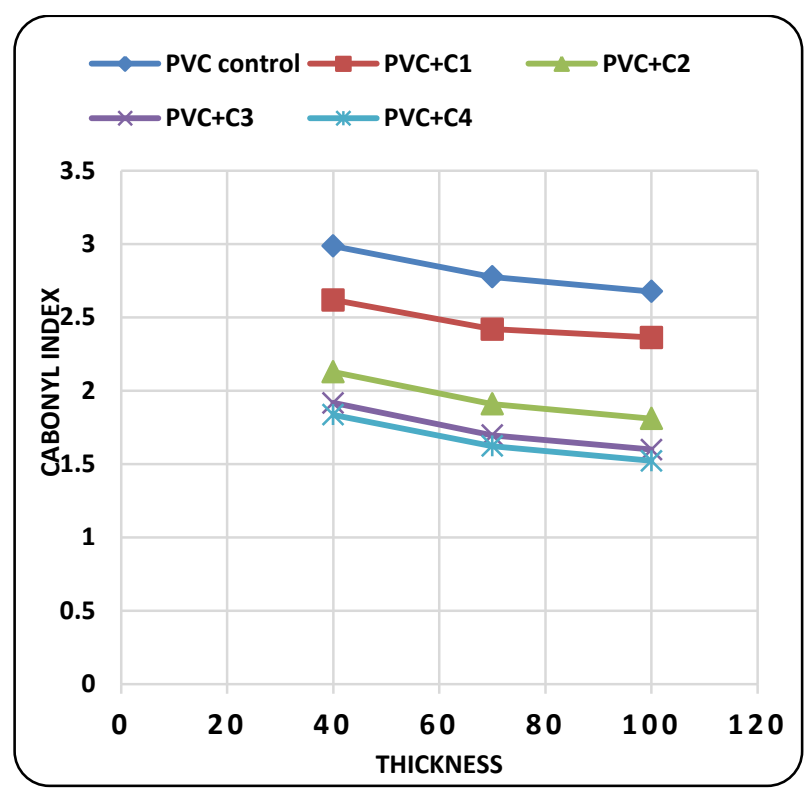

Fig.(9): The relationship between carbonyl index and film thickness ( $\mu m)$ for PVC film at 250 (hrs) irradiation time containing 0.5 $w t \%$ of additives.

Also the average molecular weight 'of the polymer degradation was calculated by viscosity measurement using equation (2) $\left[\mathrm{K}=1.5 \times 10-2 \mathrm{~g} / \mathrm{ml}, \alpha^{\prime}=0.77\right]$ and THF a solvent at $25 \mathrm{oC}$. When PVC films (with or without additive) are exposed to irradiation the intrinsic viscosity and viscosity averages molecular weight decrease with the increase of irradiation time. Fig.(10) shows the change in the molecular weight Mv, of PVC films، with and without additives after irradiations with $(0.5 \%)$ of additives.

The number of average chain ' scission (average number cut per singles chain) (S) was calculated by using the equation (7).

$$
\mathrm{S}=\frac{\overline{\mathrm{M}}_{\mathrm{vo}}}{\overline{\mathrm{M}}_{\mathrm{vt}}}-1
$$

$\overline{\mathrm{M}}_{\mathrm{v} \text { o }}$ and $\overline{\mathrm{M}}_{\mathrm{vt}}$ are the viscosity average، molecular weights before and after irradiation respectively.

The plot of (S) versus timer is shown in Fig.(11). The relation indicates an increase، in the degree of branching which might arises from crosslinking occur.

The degree off deterioration $(\alpha)$ changes with time according to the following equation (8).

$$
\alpha=\frac{\mathrm{m}}{\overline{\mathrm{M}}_{\mathrm{vo}}} \mathrm{S}
$$

Where $m$ and $\bar{M}_{v o}$ are the molecular، weights of thee monomers and polymer before irradiation respectively. The plot of $\alpha$ as a function off irradiation times is shown ' in Fig.(12) The curves indicate that the degradation is taking place by the random breaking of bonds in the' polymer chain. 


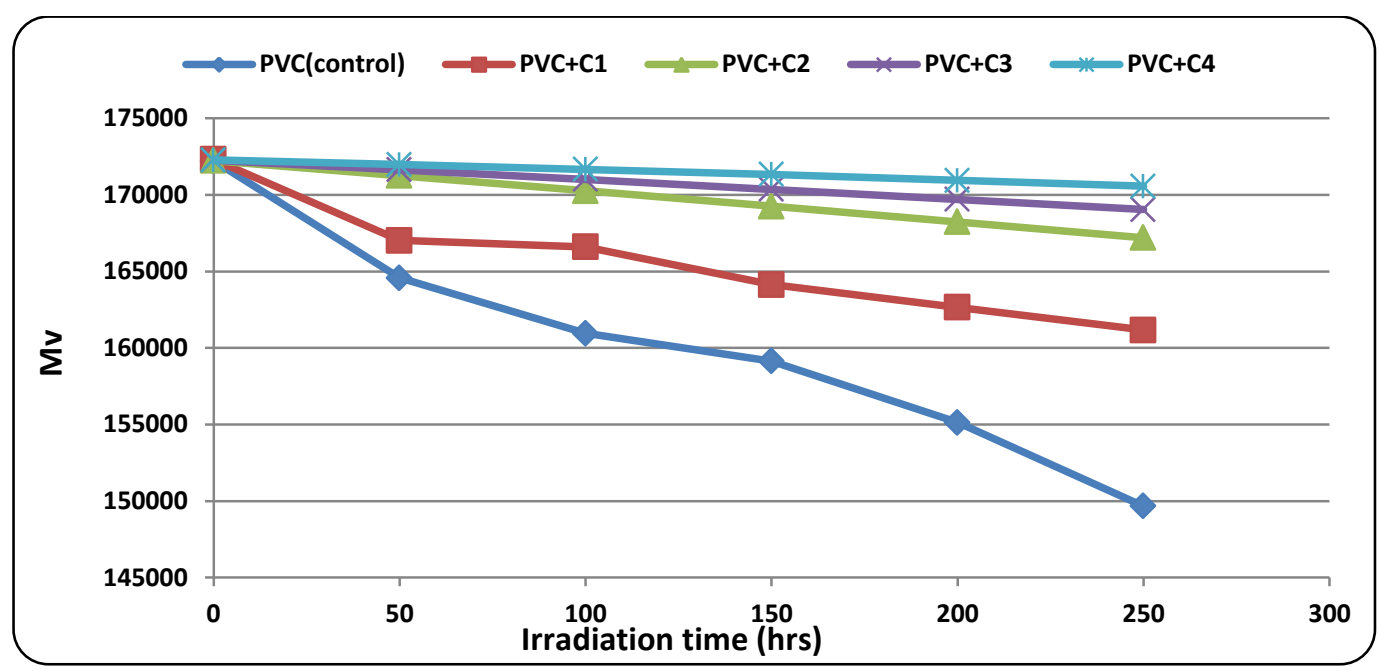

Fig.(10): Change in the viscosity average molecular weight $\left(\bar{M}_{v}\right)$ during irradiation of PVC films (40 $\mu \mathrm{m}$ in thickness) (control) and with. $.0 \%$ of additives.

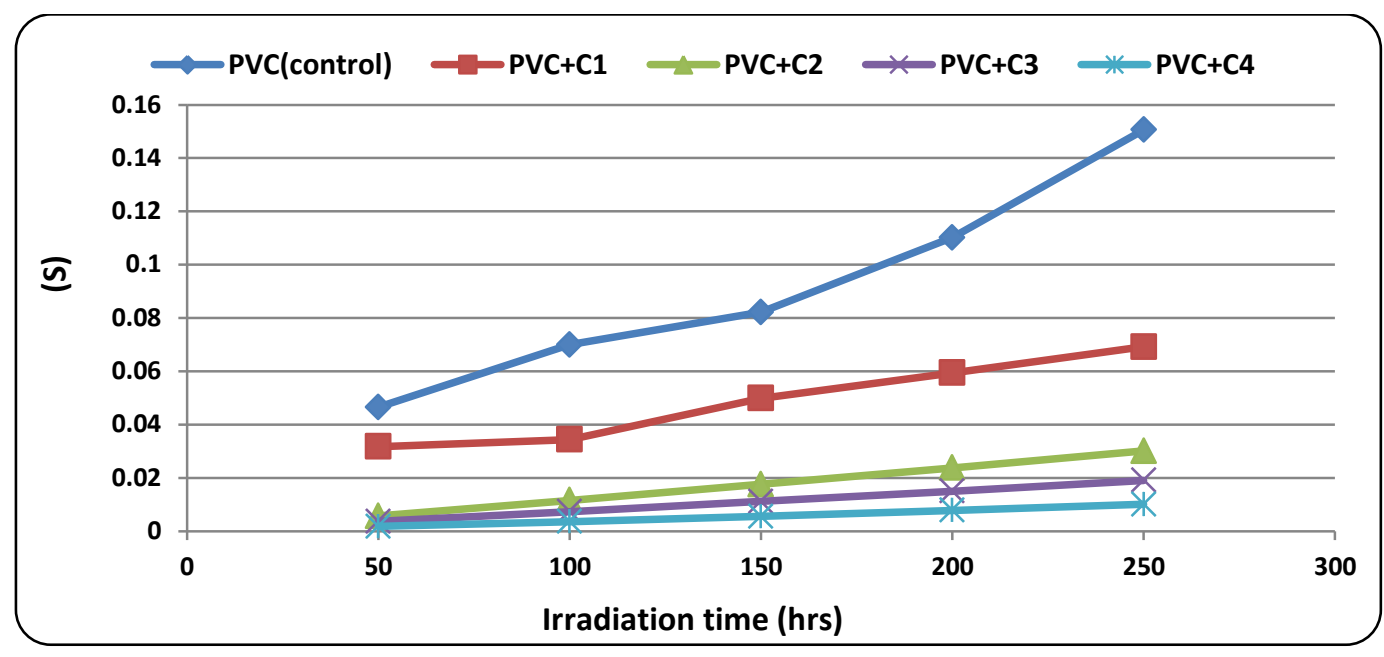

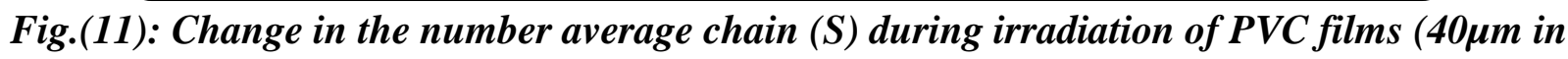
thickness) (control) and with $0.5 \%$ of additives.

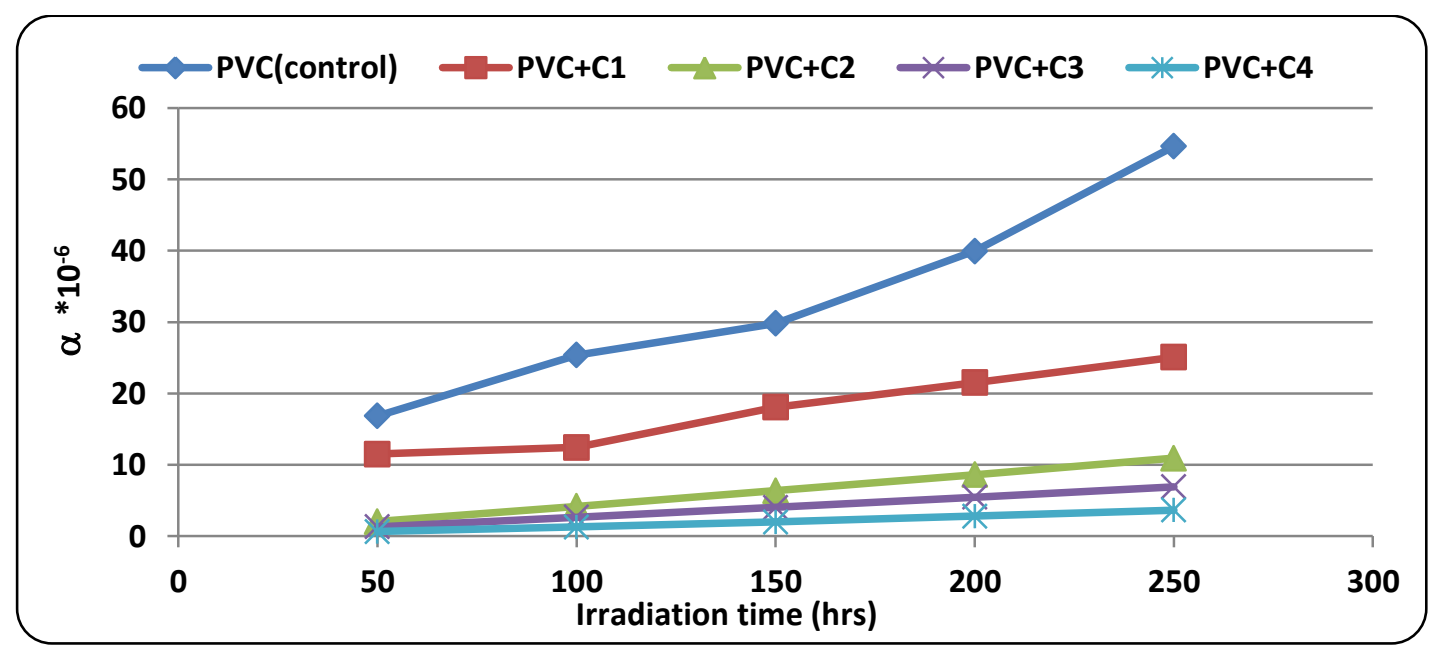

Fig.(12): Change in the degree of deterioration (a) during irradiation of PVC films (40 $\mu \mathrm{m}$ in thickness) (control) and with $0.5 \%$ of additives.

The quantum yield of chain scission $\left(\Phi_{\mathrm{cs}}\right)$ was determined by using equation (6) and it tabulated as shown in Table (2) for PVC film without additive and PVC films with $(0.5 \% \mathrm{wt} / \mathrm{wt})$ of additives. 
Table (2)

Quantum yield (Фcs) for the chain scission for PVC films (40 $\mu \mathrm{m})$ thickness with and without 0.5 (wt/wt) additive after $250 \mathrm{hrs}$. irradiation time.

\begin{tabular}{|c|c|}
\hline Additive & $\begin{array}{l}\text { Quantum yield of main } \\
\text { chain scission (Фes) }\end{array}$ \\
\hline PVC & 9.24 \\
\hline $\mathrm{C} 1$ & 4.24 \\
\hline $\mathrm{C} 2$ & 1.785 \\
\hline $\mathrm{C} 3$ & 1.106 \\
\hline$\overline{\mathrm{C} 4}$ & 0.535 \\
\hline
\end{tabular}

The (Фcs) values for PVC films without additives are more than that in the presence of additive which increases in then following trend :-

$$
\mathrm{PVC}>\mathrm{C} 1>\mathrm{C} 2>\mathrm{C} 3>\mathrm{C} 4
$$

According to then experimenta results obtained some of the mechanics were proposed. Schemes (1), (2).

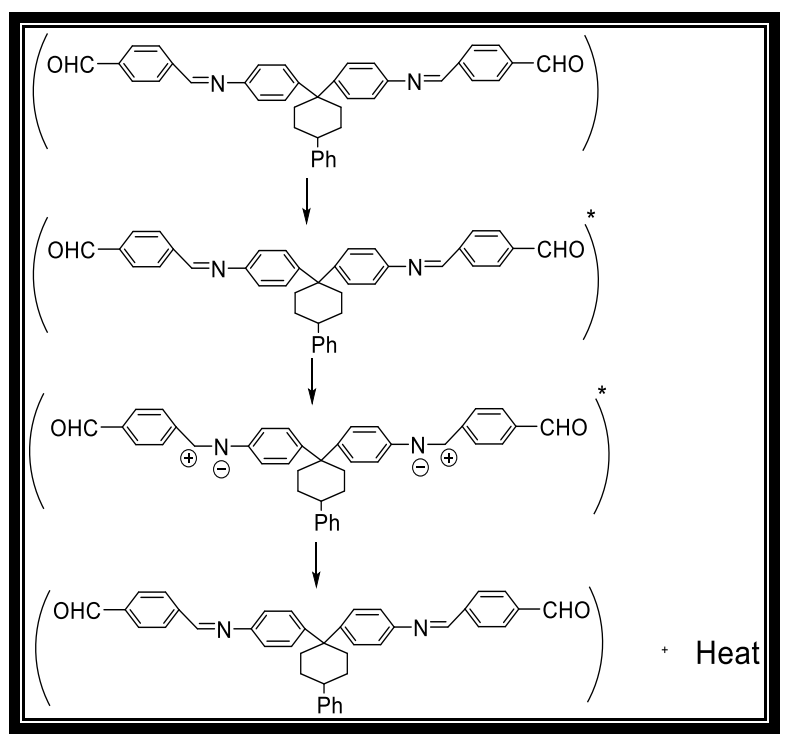

Scheme (1): The suggested mechanism of photostabilization of PVC Schiff bases compound as UV absorber[26].

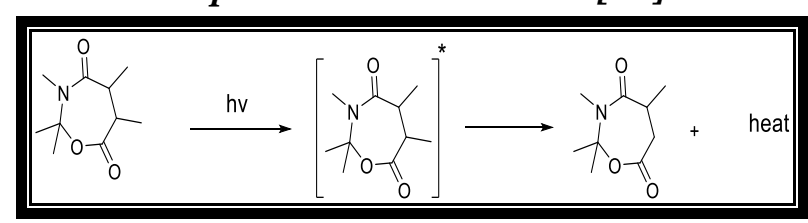

Scheme (2): Suggested mechanism of photostabilization of PVC by 1,3-oxazepine ring as $U V$ absorber [26].

Are selected compound (C2) with two different atoms of different electronagativity and polar compound explain the attraction between stabiliter and poly vinyl chloride scheme (3).

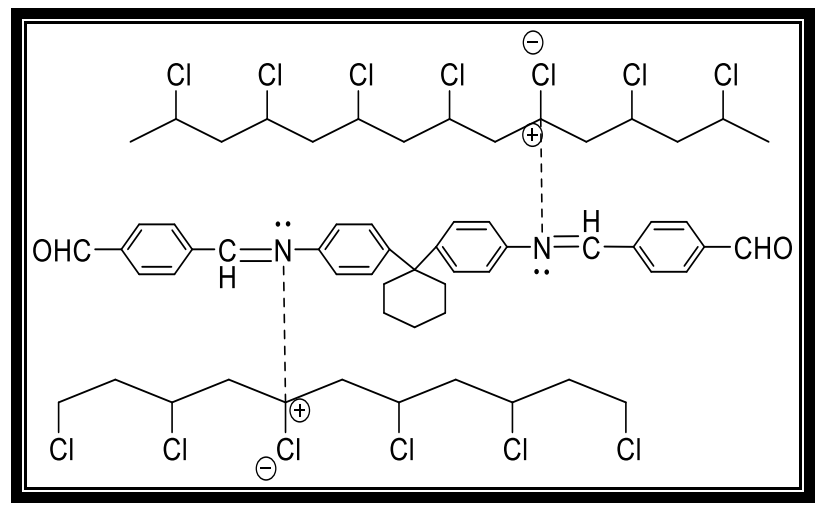

Scheme (3): Suggested mechanism of Photostabilisation of PVC by compound (C2) through the interaction between PVC and Schiff base [10].

\section{Conclusion}

The levels of photodegradation of (PVC) films containing the additives $(0.5 \%$; by weight) was reduced, with effectiveness of the additives in the order $\mathrm{C} 4>\mathrm{C} 3>\mathrm{C} 2>\mathrm{C} 1>$ PVC. For the most favorable additive (C4), the growth of the carbonyl index was reduced in comparison with the PVC without additive.

It is suggested that then additives may، help stabilizer PVC through UV absorption or screening, peroxide decomposer and radical scavenger mechanisms. The derivatives were found to be the most efficient in photostabilization process according to the photostability and mechanisms mentioned above.

\section{Acknowledgment}

The authors acknowledge the Department of Chemistry, College of Science, AlMustansiriyah University and Polymer Research Unit for their encouragement.

\section{References}

[1] Zainab H., Yousif E., Ali A., and Dheaa Z., "Study the Rate Constant of Photostabilization of PVC in Presence of Schiff's Bases of Sulphamethoxazole", J. Al-Nahrain Univ., 17(4), 39-43, 2014.

[2] Turro N. J., "Modern Molecular Photochemistry", $2^{\text {nd }}$ editio. California: Benjamin/Cummings Pub. Co, 1978.

[3] Adil A. A., Rehab A. M., Yousif E., "Study The Rate Constant of Photodecomposition of Polystyrene Films in Presence of Some 4- amino-5-(2-(6methoxynaphthalen-2-yl)piperidino)-1,2,4triazole-3-thion Complexes", J. Al-Nahrain Univ., 19 (1), 69-75, 2016. 
[4] Wiles D. M., "Photostabilization of macromolecules by excited state quenching", Pure Appl. Chem., 50(4), 291297, 1978.

[5] Sánchez-Solis A., Padilla A., "Effect of sands on poly (vinyl chloride) resistance to ultraviolet light", Polym. Bull., 36(6), 753 $758,1996$.

[6] Xiaofei Z., Tianbao Z., Hong P.,and Shaoyun Guo, "Mechanochemical preparation of a novel polymeric photostabilizer for poly(vinyl chloride)", J. Appl. Polym. Sci., 116(5), 3079-3086, 2010.

[7] Wei S., Jun Z., Xu-Ming S., and GuoDong J., "Different photodegradation processes of PVC with different average degrees of polymerization", J. Appl. Polym. Sci., 107(1), 528-540, 2008.

[8] Yousif E., Ahmed A., and Mahmoud M., "New organic photostabilizers for rigid PVC against photodegradation", Lambert Acad., 2012.

[9] Cheremision N., "Hand Book of Engineering Polymeric Materials", New York, p. Chapter 8, 1997.

[10] Olfat A. N. and Hamed g. L., "Synthesis and Identification of Heterocyclic Compounds (Oxazepine, Tetrazole) Derived from Benzidine as Photostabilizing for Poly vinyl chloride", Al-Mustansiriyah J. of Science 28(2), 28-36, 2017.

[11] Castillo F. et al., "Influence of structure on the photo-degradation of PVC. Part IVA conclusive approach to the mechanism of photo-oxidation and photodehydrochlorination", Polym. Degrad. Stab., 27(1), 1-11, 1990.

[12] Yousif E., Jumat S., and Nadia S., "New stabilizers for polystyrene based on 2thioacetic acid benzothiazol complexes", J. Appl. Polym. Sci., 125(3), 1922-1927, 2012.

[13] Olfat A. N., "Photostabilization of polyvinyl chloride by some new thiadiazole derivatives", Eur. J. Chem., 6(3), 242-247, 2015.

[14] Olfat A. N., Hussein N. S., and Luma S. A., "Synthesis, Characterization, Biological Activity Studies Of Schiff Bases And 1,3Oxazipene Derived From 1,1 -Bis (4aminophenyl) -4-Phenyl Cyclohexane", Iraqi J. Sci., 58(4B), 2017.

[15] Mustafa A., Gamal A., Hanan I., and Emad Y., "Investigation of the Photodecomposition Rate Constant of Poly (Vinyl Chloride) Films Containing
Organotin (IV) Complexes", J. Al-Nahrain Univ., 20(3), 18-23, 2017.

[16] Walter H. and Byron K., "An introduction to chemical analysis", 2nd editio. New York, 1981.

[17] Hiizu I., "High-spin polycarbenes as models for organic ferromagnets", Pure Appl. Chem., 58(1), 187-196, 1986.

[18] Bengt G. R. and Jan F. R., "Photodegradation, photo-oxidation, and photostabilization of polymers", New York, Wiley, 1975.

[19] Arct J., Dul M., Rabek J., and Ranby B., "Studies on modified benzotriazoles as photostabilizers for poly(vinyl chloride)", Eur. Polym. J., 17(10), 1041-1048, 1981.

[20] Pezzin G., Talamini G., and Vidotto G., "Polymerization of vinyl chloride. Molecular weight distribution of polyvinyl chloride during the suspension process", Macromol. Chem. Phys., 43(1), 12-22, 1961.

[21] Poh B. T. and Ong B. T., "Dependence of viscosity of polystyrene solutions on molecular weight and concentration", Eur. Polym. J., 20(10), 975-978, 1984.

[22] Ping X., Dafei Z., and Deren Z., "Studies of the thermal stability of poly(vinyl chloride)--II. Influence of molecular weight on the thermal stability of PVC", Eur. Polym. J., 25(6), 581-583, 1989.

[23] Torikai A., Ohno M., and Fueki K., "Photodegradation of poly(methyl methacrylate) by monochromatic light: Quantum yield, effect of wavelengths, and light intensity", J. Appl. Polym. Sci., 41(56), 1023-1032, 1990.

[24] Balakit A. A., Ahmed A., Gamal A., Keith S., and Emad Y., "Synthesis of new thiophene derivatives and their use as photostabilizers for rigid poly (vinyl chloride)", Int. J. Polym. Sci., 2015, 2015.

[25] Yousif E., Jumat S., Nadia S., Ali J., and Yip-Foo W., "New stabilizers for PVC based on some diorganotin (IV) complexes with benzamidoleucine", Arab. J. Chem., 9, S1394-S1401, 2016.

[26] Ayad H., "Microwave synthesis of some New 1, 3-oxazepine compounds as photostabilizing additives for PMMA films", J. Al -Nahrain Univ., 15(4), 47-59, 2012. 